\title{
Culto y culturas en la cueva de Gorham (Gibraltar): La historia del santuario y sus materiales inscritos ${ }^{1}$
}

\author{
Worship and cultures in Gorham's cave, (Gibraltar): \\ the sanctuary history and its written items
}

\author{
José Ángel Zamora López ${ }^{*}$ José Ma Gutiérrez López ${ }^{* *}, M^{\mathrm{a}}$. Cristina Reinoso del Río **, \\ Antonio M. Sáez Romero ${ }^{* * *}$, Francisco Giles PaCheco ${ }^{* * * *}$, J. Clive Finlayson ${ }^{* * * *}$, \\ Geraldine FinLAYSON***** \\ *Instituto de Lenguas y Culturas del Mediterráneo y Oriente Próximo (CSIC). C/ Albasanz 26-28. E - 28037, Madrid \\ (España) \\ joseangel.zamora@csic.es \\ ${ }^{* *}$ Museo Histórico Municipal de Villamartín. Avenida de la Feria, s/n. E- 11650 Villamartín (Cádiz, España) \\ museovillamartin@hotmail.com \\ mcristinareinoso@yahoo.es \\ *** Área de Arqueología, Universidad de Cádiz. Facultad de Filosofía y Letras. Avenida Dr. Gómez Ulla, s/n. E - 11003 \\ (Cádiz, España) \\ antonio.saez@uca.es \\ ${ }^{* * * *}$ Gibraltar Caves Project. C/ Lebrillo 46. E - 11500 El Puerto de Santa María (Cádiz, España) \\ pacogiles@telefonica.es \\ ***** Gibraltar Museum. 18-20, Bomb House Lane. PO Box 939 Gibraltar \\ clive.finlayson@gibmuseum.gi \\ geraldine.finlayson@gibmuseum.gi
}

Recibido: 26-06-2012

Aceptado: 06-02-2013

\begin{abstract}
Resumen
El artículo presenta un nuevo estado de la cuestión arqueológico sobre el santuario protohistórico de la Cueva de Gorham (Gibraltar) a la luz de los resultados de las recientes campañas de excavación y estudia los materiales cerámicos con inscripciones $u$ otro tipo de marcas hallados en la cueva. El catálogo incluye un nuevo grafito fenicio y una inscripción greco-ibérica que se relacionan con las ofrendas depositadas en el lugar desde época arcaica hasta el periodo helenístico.
\end{abstract}

Palabras Clave: Arqueología / Epigrafia. Fenicios. Iberos. Mediterráneo Occidental. Lugares de culto.

\begin{abstract}
This paper presents an updated overview of the ongoing archaeological research carried out in the Protohistoric sanctuary of Gorham's Cave (Gibraltar). It is based on the results of recent excavations, focusing on incised pottery with inscriptions or other marks. The catalogue of inscriptions includes both Phoenician and Graeco-Iberian examples, which could be related with the deposition of votive offerings from Archaic to Hellenistic periods.
\end{abstract}

KeY words: Archaeology. Epigraphy. Phoenicians. Iberians. West Mediterranean. Cultic Places. 


\section{Introducción}

Las antiguas Columnas de Hércules constituyeron un hito geográfico, pero también un lugar investido de significación simbólica, un espacio sumido en el terreno de los mitos de las civilizaciones mediterráneas. El Estrecho que separa el Mediterráneo del Atlántico marcó también el confín occidental del mundo humano conocido y civilizado, bordeado por el Océano según la concepción griega del Orbe. La literatura científica generada a partir de las fuentes geográficas y periplos náuticos antiguos conservados (desafortunadamente casi exclusivamente grecorromanos, con escasa información propiamente púnica) puede considerarse actualmente como ingente (López Melero 1988: 615-642; Antonelli 1997; Pérez 1998; López Pardo 2000: $25-$ 33; González Ponce 2008: 59-74; González Wagner 2008: 11-29).

En trabajos recientes se ha puesto de relieve el importante papel de las columnas heracleas como límite, normalmente referenciado por los autores griegos de una forma imprecisa, distante y nebulosa, que separaba el mundo que les era propio de otro completamente ajeno y desconocido, que ofrecía así un marco ideal para la ubicación de tierras y sucesos mitológicos que desde la época homérica se encontraban en constante desplazamiento hacia Occidente (González Ponce 2008: 69, con amplia bibliografía anterior). Las particularidades geográficas y de navegación del Estrecho y del propio peñón rocoso gibraltareño, situado en un área crítica de paso hacia el ignoto y peligroso océano (Ruiz de Arbulo 1990: 79-116), sin duda ayudaron decisivamente a la activa participación de esta zona en la configuración de la sacralización de los accidentes geográficos más destacados y en la generación de un amplísimo catálogo de citas y descripciones sobre el lugar en diversos momentos de la Antigüedad (González Ponce 2008: 66-67). Esta situación como tópico geográfico extremo-occidental se habría prolongado probablemente hasta finales del s. IV a.C. o el s. III a.C., momento en el que las descripciones literarias griegas comienzan a situar el extremo del mundo más allá de las propias Columnas $(C f$. Eratosthenes, frag. II C 18, Berger 1964).

La cueva-santuario de Gorham, situada en la base de la columna europea (repetidamente citada como Calpe por diversos escritores antiguos), se integra en una cada vez más densa red de cavidades que jalonan el Mediterráneo y que parece estuvieron en buena medida vinculadas a cultos con fuerte componente ctónica relacionados con funciones oraculares y de salvaguarda del tráfico comercial marítimo (Lipiński 1995: 423-427; Gómez y Vidal 2000: 103-145; Marín, 2010: 219-244; Ruiz Ca- brero 2010: 109-119). En este sentido, el ejemplo gibraltareño se erige actualmente como el referente historiográfico más destacado del litoral del Estrecho y costas atlánticas, con un volumen de datos mucho más contundente que otros casos, como el santuario citado por Avieno en la propia Gadir y dedicado a Astarté, que sólo nos consta gracias a las fuentes literarias y -según algunos autores- a un heterogéneo conjunto de hallazgos de origen subacuático (síntesis recientes en Marín, 2010: 235 y Marín, 2011: 545).

A los ya numerosos datos aportados por los hallazgos materiales del santuario hay que añadir ahora algunos más: en las páginas que siguen se presentan los materiales cerámicos inscritos o marcados procedentes de los trabajos arqueológicos antiguos $\mathrm{y}$ recientes en el yacimiento. El estudio y publicación de estos materiales se acompaña de una previa síntesis arqueológica actualizada del estado de la cuestión sobre la Cueva de Gorham, especialmente necesaria a la luz de los resultados de las campañas de excavación desarrolladas en los últimos años. Éstas han arrojado datos de enorme interés acerca de la composición material de las ofrendas del santuario, de la cronología de funcionamiento $\mathrm{y}$ del diverso origen de los marinos y devotos que se acercaron a la cavidad para realizar los rituales oportunos. Este será el contexto en el que enmarcar los materiales inscritos o marcados estudiados en la segunda parte del artículo, que aportarán datos añadidos sobre los que elaborar unas primeras conclusiones acerca del especial carácter del santuario y su rica historia.

\section{Aspectos generales}

El Peñón de Gibraltar es una pequeña península calcárea de unos $6 \mathrm{~km}^{2}$ de superficie y $426 \mathrm{~m}$ de altura, alargada en dirección meridiana unos $5,2 \mathrm{~km}$, con perfil asimétrico, acantilado al Este en la vertiente que se abre al Mediterráneo y más tendido al Oeste hacia el interior de la Bahía de Algeciras. Se sitúa en el extremo Sur de la Península Ibérica $\left(36^{\circ} \mathrm{N}\right.$ $05^{\prime} \mathrm{O}$ ) a $21 \mathrm{~km}$ de la costa norteafricana (fig. 1). La Cueva de Gorham se encuentra en la base del acantilado suroriental de Gibraltar.

La cavidad es una galería larga y bastante estrecha con un desarrollo total de $102 \mathrm{~m}$ que desde un monumental vestíbulo con una bóveda de $40 \mathrm{~m}$ de altura va estrechándose progresivamente. La zona central que inicia la galería de la cavidad propiamente dicha, fue el área donde se realizaron las excavaciones dirigidas por John d'Arcy Waechter durante 1948, 1950-1951, 1951-1952 y 1953-1954, que dieron notoriedad general al yacimiento por su 


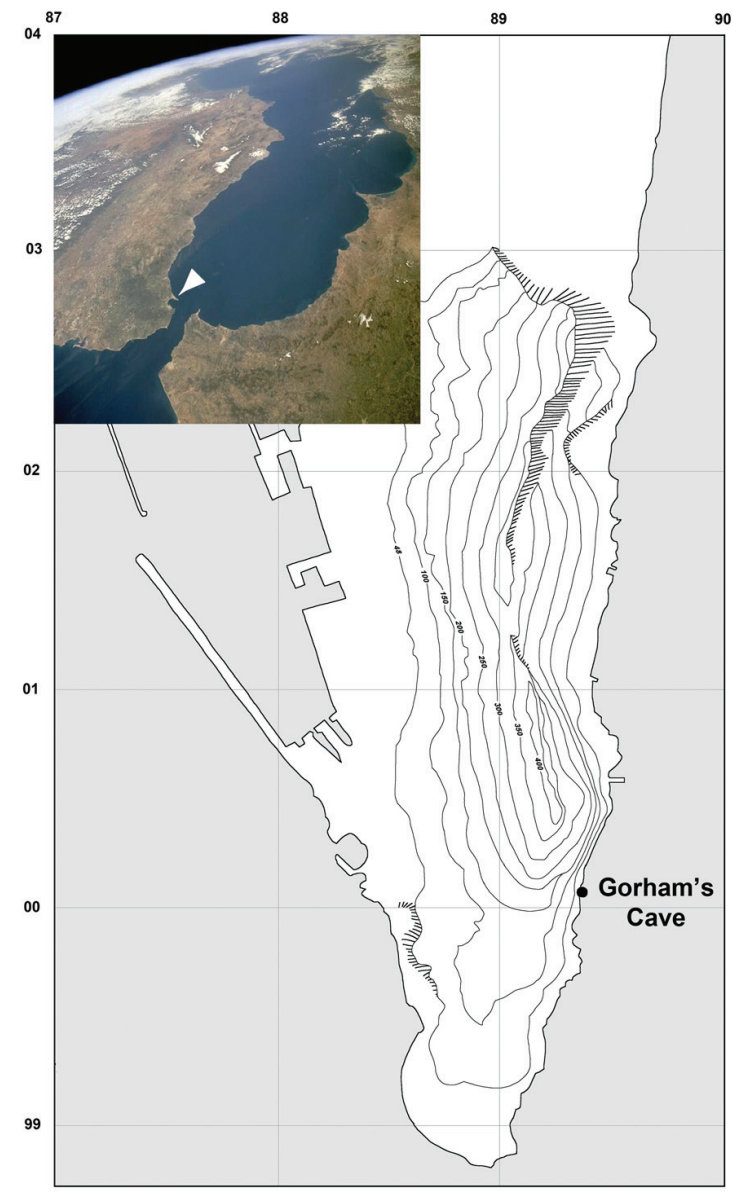

Fig. 1.- Emplazamiento de la cueva de Gorham en la base del acantilado suroriental de Gibraltar, al extremo Sur de la Península Ibérica.

amplia secuencia estratigráfica (Waechter 1951: 83; Idem 1964: 189), y hoy es el lugar con la morfología original más transformada. A partir de una gran columna estalagmítica se inicia el tramo interno, con un primer sector longitudinal de $28 \mathrm{~m}$ de longitud y una amplitud oscilante entre 5 y $2 \mathrm{~m}$, donde se recuperan los caracteres propios de un espacio subterráneo sin influencia de la luz exterior. En este lugar de la cueva se están desarrollando las investigaciones actuales.

El yacimiento cuenta con una dilatada historiografía de investigaciones que se inicia en 1907 con su exploración por parte del militar británico que nomina la cavidad (Finlayson 1994: 2-5). No obstante, no será hasta el primer estudio riguroso del registro prerromano recuperado hasta entonces cuando se incorporará al debate sobre la presencia fenicia en Occidente (Culican 1972: 110-145). Después y hasta el inicio del presente Proyecto solamente el trabajo de revisión de los fondos de esas antiguas excavaciones realizado por las Universidades de Cádiz y Sevilla se había centrado en la utilización protohistórica de la cavidad (Belén y Pérez 2000: 532).

Desde 1997, la investigación de las manifestaciones cultuales del primer milenio que se materializaban en el nivel final de la secuencia, se involucró como una parte específica de los objetivos generales del Gibraltar Caves Project (Gutiérrez et al. 2001a: 13-30; Gutiérrez et al. 2001b: 16-20; Gutiérrez et al. 2012: 2955-2970; Gutiérrez et al. 2013: 303-381; Gutiérrez et al. e.p. a; Gutiérrez et al. e.p. b), iniciativa liderada desde el Gibraltar Museum, con el concurso de un equipo multinacional y multidisciplinar, dirigido por dos de nosotros (J. C. F. y F. G. P.), junto a J. Rodríguez Vidal de la Universidad de Huelva. Los trabajos de excavación y estudio aún continúan, aunque los resultados que se exponen aquí proceden principalmente del análisis arqueológico de los materiales obtenidos en el periodo comprendido entre 1997 y 2004.

A día de hoy Gorham continua siendo referencia y foco de interés en la investigación sobre la religiosidad fenicio-púnica (Pérez 1998; Belén 2000: 58-62; Gómez y Vidal 2000: 113-114; Ferrer 2002a: 185-217; Idem 2002b: 111-112; Martín 2007: 110-111 y 173-174; Marín, 2010: 230232) y sus principales manifestaciones materiales (Hawkes 1980; Padró 1976: 56-62; Idem 1985: 128-149; Idem 1994: 95-98; Idem 1995: 154-167; Posadas 1988: 517-527; López 1990: 98-108; López 1995: 119-127; Mancebo 1995: 83-86; Belén y Pérez 2000: 531-542; Gómez 2002: 108-110; Velázquez 2007: 82-86), por lo que se constituía en un objetivo del máximo interés científico la actualización de los conocimientos que sobre el registro cultual pudieran conservarse en la cavidad.

\section{Síntesis de la secuencia del santuario}

Los objetos recuperados en Gorham constituyen el testimonio de la acumulación recurrente de ofrendas y otros actos rituales realizados por devotos que recalaban en el santuario. Su situación clave en el confín occidental del Mediterráneo y a las puertas del Océano convierte a la cavidad en un magnífico laboratorio desde el cual acercarse al análisis del tránsito de mercancías que tenía lugar entre ambos mundos y a los actores de dichas navegaciones. Los nuevos estudios pretenden ahondar en esta perspectiva, profundizando en la determinación de talleres de procedencia de las ofrendas, sin prescindir de aproximaciones a la religiosidad fenicio-púnica. 
Los datos disponibles actualmente permiten clarificar el inicio del uso cultual de la cueva en el periodo arcaico, a finales del IX a.C. o principios del VIII a.C, según la serie de dataciones calibradas disponible (Beta 184053, 185544 y 185545, que han aportado, respectivamente, los siguientes resultados: $2500 \pm 40,2460 \pm 40,2450 \pm 40$ BP / 800-520, 780-410, 780-410 CAL 2 $\sigma$ BC; vid. Gutiérrez et al. 2013: 319-320; Gutiérrez et al. e.p. a). En este momento están presentes diversas ofrendas de origen fenicio oriental, y las producciones anfóricas y de barniz rojo fenicias de la costa mediterránea andaluza del horizonte B1 de Morro de Mezquitilla (Ramón 2006: 192-195; Idem 2010: 218-219). En todo el desarrollo arcaico hasta el siglo VI a.C. quedarán bien atestiguados los productos del Grupo Málaga, los del ámbito cartaginés metropolitano (Gutiérrez et al. 2012: 2960-2963) y especímenes centromediterráneos de origen nurágico y procedentes de las colonias fenicias insulares, además de un grupo importante englobado bajo la denominación de Occidental indeterminado, que corresponden a un número no concretado de centros fenicio-occidentales coloniales e indígenas de tipo orientalizante. De éstos procederían cerámicas a mano características del mundo tartésico, algunas grises a torno, pintadas y de barniz rojo. Una representación más precisa -centrada en época tardoarcaica- ofrecen los productos claramente asignados a la Bahía de Cádiz, manufacturas incluidas en la conocida tónica de despegue productivo de escala mediterránea de las alfarerías gadiritas, operado al calor del ascenso de la industria pesquero-conservera (Sáez 2008: 141; Idem 2010: 303-312; 2011: 278-285). Del mismo modo, en esta fase se sitúan también elementos que suponen la confirmación de la presencia de cerámicas greco-orientales arcaicas en este punto intermedio del Estrecho. También en esta fase destaca el importante conjunto de escarabeos en esteatita y pasta vitrificada de factura egipcia (Padró 1985: 128-149) y de otros talleres mediterráneos (Gorton 1996: 153) junto a otras ofrendas sobre diferentes soportes materiales.

El contexto arqueológico de la fase púnica no es sino el reflejo fiel de la intensificación de la circulación por el Estrecho, que comporta la consolidación de un culto en el santuario que habían iniciado los navegantes mediterráneos en la etapa arcaica. De nuevo se vuelven a registrar productos de orígenes heterogéneos, pero la representación de cada centro productivo configura un panorama comercial distinto de la fase arcaica, con el auge de áreas anteriormente poco significativas en detrimento de las antaño con potente presencia, y novedades como la aparición de producciones ebusitanas, tingitanas, turdetanas y áticas, éstas últimas importaciones de una facies característica del s.V a.C. (Gutiérrez et al. 2013: 348-349). Caso paradigmático será la expansión cuantitativa de las manufacturas gadiritas procedentes de sus talleres insulares (Ramón et al. 2007: 115-119; Sáez 2008: 524) que toman el relevo de otros centros tradicionales como los de la costa mediterránea peninsular, y certifican un flujo de mercancías atlánticas circulando en dirección mediterránea que también hace escala en el santuario. Igualmente destacable será el mantenimiento constante de la llegada de elementos de origen tunecino, además acompañados por otros elementos vasculares centromediterráneos (Gutiérrez et al. 2013: 341-342). En esta línea conviene hacer referencia al grupo de escarabeos que pueden datarse en esta fase púnica sobre soportes de vidrio y jaspes de probable procedencia sarda (Moscati 1987: 111114; Olianas 2009: 363-369; Guirguis et al. 2010: 115-116), fruto del tráfico comercial realizado desde los grandes centros redistribuidores mediterráneos, con estrechas concomitancias temáticas en la glíptica centromediterránea en general, y ebusitana en particular (Boardman 1984: 82-91).

Los últimos momentos del santuario muestran un perfil de importaciones muy característico (Gutiérrez et al. 2013: 353-359), integrado por la asociación de cerámicas campanienses A, ánforas grecoitálicas campanas y cerámicas ibéricas como kalathoi y jarritas bicónicas grises, así como con ungüentarios globulares cartagineses, que es bien conocido en múltiples horizontes tanto terrestres como subacuáticos de esta etapa, en especial del s. II a.C., conformando una facies muy característica de los circuitos comerciales occidentales (Bernal et al. 2007: 338-353; Bridoux 2008: 425-434; El Khayari 2004: 155-168; Bernal et al. en prensa), presente de manera idéntica en Cartago (Morel 1988: 67-100). Este conjunto material de importaciones junto a las últimas producciones helenísticas regionales, permiten fijar el ocaso del culto en Gorham hacia la mitad del s. II a.C., cuestión que se debe poner en relación con el proceso de colonización y aculturación romana del ámbito de las Columnas ejercido a través de iniciativas como la deductio de la Colonia Libertinorum Carteia (171 a.C.) y la definitiva liquidación de Cartago (146 a.C.) como potencia comercial autónoma.

En definitiva, el estudio del material hallado en el nivel protohistórico de la Cueva de Gorham revela una creciente riqueza y variedad correspondiente a una historia larga y compleja, a su vez construida por frecuentaciones de muy diversa caracterización. Por su especial naturaleza, el santuario debió en efecto ser progresivamente visitado por gentes de muy diverso origen y cultura, convirtiendo el enclave en un centro cuya liturgia e identidad fue forjada 

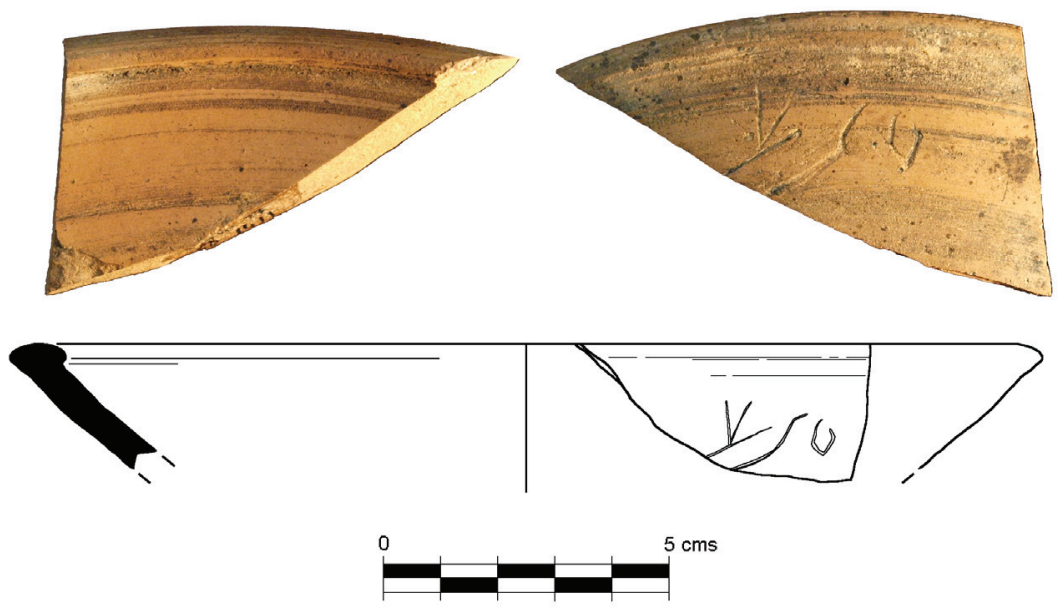

Fig. 2.- Fotografía y dibujo arqueológico de la pieza GOR-166.

a lo largo del tiempo en que estuvo en uso, más que por una tradición cultual definible e invariable (difícil de proponer además para un contexto tan diverso del concepto de templo más común), por un continuo interactuar cosmopolita.

En cualquier caso, quedan aún muchas cuestiones abiertas, tanto en la comprensión del rico material que refleja la historia del santuario (por ejemplo, en la definición de los procesos de deposición de las ofrendas) como en su interpretación de conjunto (desde las formas de mantenimiento de la propia gruta a los particulares de su frecuentación multicultural). Una serie de informaciones más deben ser añadidas e integradas al respecto: entre los hallazgos que reflejan la historia del lugar de culto se encuentran algunos materiales inscritos. Como veremos a continuación, permiten de forma significativa la caracterización cultural, en perspectiva histórica, de algunos de los frecuentadores de la cueva.

\section{El grupo de materiales inscritos o marcados}

En efecto, diferentes materiales hallados en el yacimiento, todos ellos cerámicos, presentan incisiones intencionadas, correspondientes a inscripciones y marcas. Se trata de nueve piezas, una cantidad de testimonios bastante reducida -especialmente si se juzga en proporción a la abundancia de restos proporcionados por el yacimiento- pero de una representatividad llamativa. Las piezas se hallaron tanto en actuaciones antiguas como recientes y, una vez datadas, se demuestran pertenecientes a fases muy variadas. No menos variadas son sus características, puesto que salvo las marcas más simples (que tienden a repetir unos mismos esquemas) en Gorham los materiales con incisiones intencionadas presentan bastante diversidad en su trazado, posición y entidad. Reforzando este cuadro general de variedad, los dos documentos que pueden ser calificados como inscripciones son, a su vez, distantes en cronología, diferentes quizá en función y, sobre todo, pertenecientes a tradiciones gráficas y lingüísticas del todo diversas.

Estudiamos a continuación este conjunto de documentos, comenzando por los dos seguros objetos con epígrafe para después presentar, más brevemente, los que más bien parecen corresponder a recipientes con marcas no grafemáticas. Dentro de cada grupo, damos la sucesión en orden cronológico, lo que nos proporcionará en cierto modo una representación material selecta de la historia del santuario, historia cuya reconstrucción exponíamos en los primeros apartados.

\section{Inscripciones}

5. 1. La pieza más antigua de las dos con seguridad inscritas con un texto (del que se hizo una primera presentación en Gutiérrez et al. e.p. b) es un fragmento de cuenco de cerámica común, pero cuidada (pieza cuya sigla en el catálogo arqueológico del yacimiento es GOR-166). En el fragmento se conserva parte del borde (triangular y redondeado al exterior, prácticamente en gancho al interior) y el arranque del cuerpo troncocónico. Sus dimensiones son: $\mathrm{H}=20, \varnothing=$ borde $180, \mathrm{E}=04 \mathrm{~mm}$; su pasta es anaranjada-rojiza, compacta, con pequeñas partícu- 


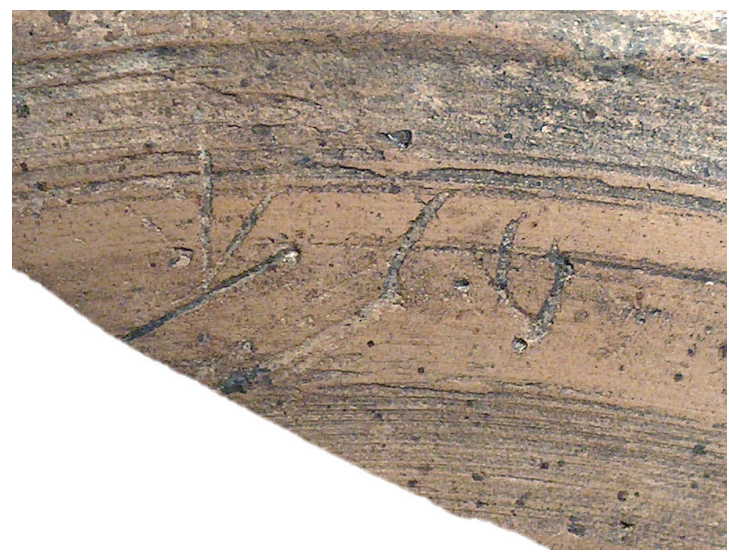

Fig. 3.- Detalle fotográfico del grafito sobre la pieza GOR-166.

las calizas -casi inapreciables- como desgrasante; tanto la superficie interior como la exterior se presenta pulida en bandas, sin más decoración. Parece tratarse de una producción greco-oriental de época tardoarcaica. Era pues parte de un objeto común, pero importado y de cierta calidad.

En la cara externa del cuerpo de la pieza, en la primera banda lisa bajo el borde, pero superponiéndose también a las zonas estriadas, se distingue con facilidad un grafito, inciso post-cocción. Los trazos dibujan 3 signos, claramente identificables como grafemas fenicios (figs. 2 y 3 ).

\section{- Lectura y paleografía}

Los tres grafemas se hallan incisos con trazos claros, decididos y profundos, sin aparentes retoques y apenas alargamientos indeseados; muestran sin embargo las claras dificultades impuestas a su trazado por una superficie dura y con alguna estría o imperfección. Estas dificultades se revelan sobre todo en el trazado de las líneas curvas, que reducen los giros en parte de su recorrido y se hacen más imprecisas. Se trata de características típicas de los grafitos sobre cerámica (fig. 4).

El primer grafema (leyendo de derecha a izquierda, el sentido típico de la escritura alfabética fenicia a la que los signos pertenecen) es un claro 'ayin. Fue inciso en dos trazos, quedando abierto en su parte superior izquierda y presentando un alargamiento en su parte inferior derecha. Aunque estas aperturas y alargamientos son resultado de la difícil incisión de grafemas sobre superficies cerámicas, son también fruto y muestra de su modo de trazado, apreciable en muchas de las inscripciones pintadas y reflejado en diferentes periodos de forma esporádica en las inscripciones monumentales, incluso

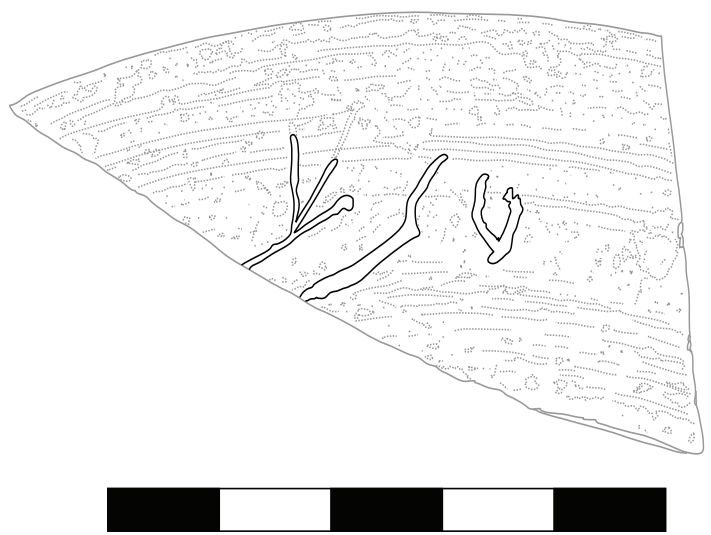

Fig. 4.- Dibujo epigráfico del grafito fenicio inciso en la pieza GOR-166.

en aquellas de mejor factura donde no es rara, por ejemplo, la presencia de la letra 'ayin de tipo abierto [Recuérdese p. ej. la inscripción bibliota conocida como la del "Hijo de Sipithbaal" (KAI 9, que suele datarse al final de la centuria a la que también parece pertenecer el grafito o poco después) o la inscripción de Yehawmilk (ya del s. V a.C.) ambas con algunos de sus 'ayin abiertos en su parte superior. En Occidente, el 'ayin abierto se hace muy presente en las inscripciones púnicas, pero su trazado en dos gestos se aprecia tan tempranamente como queramos datar el famoso medallón de Cartago (ciertamente peculiar, en virtud de su incisión sobre metal, pero significativo). Por lo demás, las series cursivas confirman la continuidad tanto del trazado en dos gestos como de las eventuales aperturas desde antiguo y hasta época tardía. Vid. p. ej. Friedrich et al. 1999: taf. II.1, 3; III.3; IV; V, 4-9; Peckham 1968: pl. IV.2; VII.4; X-XI; XII-XV]. El grafema de la pieza que nos ocupa es pues perfectamente compatible con la datación arqueológica del objeto en el periodo tardoarcaico.

El segundo signo es una nun, muy condicionada por la incisión de sus formas en la superficie cerámica, pero difícil de confundir con otros grafemas (puesto que, dada su inclinación y el trazado de su extremo superior, difícilmente podría tratarse de una waw). Está ejecutada casi en un único gesto, con sólo un vértice anguloso, característica también conocida en ejemplos occidentales del grafema de la misma época [vid. p. ej. la nun presente en la laminilla de Pyrgi (KAI 277), datada también habitualmente a finales del s. VI a.C.].

El tercer signo, más extraño y ambiguo, debe corresponder a una shin (algo particular) o a una kaph (también algo rara). En el s. VI a.C., la letra shin debió presentar (tanto más en la escritura co- 
mún de los grafitos) un dibujo en tres trazos ("en tridente") que había sustituido al grafema arcaico de cuatro trazos ("en W"). Este tipo de grafema presenta algunas variantes (ciertas de ellas arcaizantes, otras más novedosas) debiendo ser muy común en la época, también en Occidente, aquella que unía sus tres trazos en un único vértice inferior [vid. p. ej. la ya citada inscripción de Pyrgi (KAI 277) o las aún algo más antiguas inscripciones de Sulcis (CIS 147) o algunas de Mozia; véase de nuevo Friedrich et al. 1999: taf. III, 6-8]. Tal pudo ser el patrón que subyacía a la letra presente en el grafito de la cueva de Gorham. Sin embargo, en este caso el trazo derecho (el último en ser dibujado) se alarga intencionadamente (puesto que no se trata de un mero sobrepaso) formando un astil similar al de la propia nun anterior. Este alargamiento del trazo no es normal en la epigrafía monumental del periodo; sólo se atestigua en momentos posteriores [cuando el grafema ya ha cambiado, como se advierte p. ej. en época helenística o romana en algunos testimonios con el astil especialmente alargado del área de Tiro; o, en Occidente, en algunos de Malta; las inscripciones púnicas muestran el alargamiento de este trazo de manera general, como parte definitoria de un signo en fuerte evolución, aunque en general raras veces se alarga en demasía; vid. p. ej. Friedrich et al. 1999: taf. II 8-9, 11; IV; Peckham 1968: pl. II-III, V-VI; XIIXIV]; confirma no obstante el modo de trazado y la tendencia gráfica [como dejan también ver los testimonios pintados, Friedrich et al. 1999: taf. V, esp. 8-9; Peckham 1968: pl. X.7]. Es pues posible que nos encontremos ante una shin con un largo y extraño astil derecho, letra que habría que suponer propia de formas de la escritura común poco atestiguadas, pero vigentes, en el s. VI a.C.. Si debiera en cambio tratarse de una kaph, deberían justificarse otras particularidades. El grafema presenta de forma regular en la época un largo astil con la misma inclinación que tiene el que estudiamos, pero la evolución del signo le había llevado a presentar desde fases anteriores su característico ángulo superior con líneas simples, cortas y no siempre convergentes (véase de nuevo Friedrich et al. 1999: taf. I, 9-14; II, 1-3.), de manera muy diversa al gran abanico formado por las dos largas incisiones con vértice común del signo de la cueva de Gorham. No obstante, algunos ejemplos arcaizantes de la letra mantienen un cierto tamaño y amplitud en el trazado de este ángulo, aún convergente, con algún ejemplo más o menos contemporáneo del grafito que nos ocupa (también ajeno a la epigrafía monumental, también con condicionantes de incisión), no muy diferente en proporciones e inclinación [caso por ejemplo de las kaph presentes en los grafitos de Abu Simbel (CIS I 112) que suelen datarse en la primera mitad del s. VI a.C.].
El espacio vacío apreciable antes del grafema derecho y, aunque menor, también aquel disponible entre la rotura y el grafema izquierdo, indican que el grafito constaba sólo de tres letras (o que, al menos, esta secuencia de tres letras era una unidad en sí misma). La lectura de la inscripción debe ser por tanto ' $n \check{s} / k$ (esto es: la secuencia es o bien ' $n s ̌$ o bien ' $n k$ ).

\section{- Interpretación y comentario}

Los grafitos sobre cerámica de tipo similar al hallado en la cueva de Gorham suelen corresponder a nombres personales. Estos antropónimos realizan al fin y al cabo funciones de marca. Situados en zonas de la pared exterior del recipiente, como en este caso, suelen corresponder a marcas de propiedad, siendo los grafemas el nombre completo o la abreviatura del nombre de un más que probable propietario. Pero las secuencias ' $n s ̌$ o ' $n k$ no corresponden a ningún antropónimo fenicio-púnico completo conocido (tampoco en la tradición cananea atestiguada) [vid. Benz 2004: 148 y ss; Olmo y Sanmartín, 2004: 167 y ss] y, aunque podría muy bien tratarse de la abreviatura de un nombre personal, muy común en este tipo de epigrafía, tampoco ésta es clara. Las abreviaturas trilíteras son hasta cierto punto más fáciles de reconstruir que las bilíteras o unilíteras: la primera letra debería corresponder a la inicial del nombre, siendo las dos siguientes parte del resto de la estructura consonántica del antropónimo (pudiendo, sin ser sin embargo un uso regular, corresponder alguna a la inicial del segundo elemento del antropónimo y la última a su final; sobre los usos principales de abreviado en la epigrafía fenicio-púnica y su comprensión, vid. siempre Chabot 1945: 217-244 y 237-244). No faltan de hecho antropónimos fenicios y púnicos de 'ayin inicial (muy numerosos en virtud, por ejemplo, de la gran variedad de compuestos de ' $b d$-). Pero tanto si partimos de la lectura ' $n s ̌$ como de ' $n k$, ninguno de los nombres atestiguados parece resolver convenientemente la hipotética abreviatura (Benz 1972: 148-175; diferente hubiera sido el caso si la secuencia, en lugar de ' $n \check{s}$, hubiera sido 'šn, pues la abreviatura habría podido corresponder entonces al más que bien conocido ' $b d s ̌ m n$, por ejemplo, del mismo modo que, de leerse ' $k n$ en lugar de ' $n k$, estaríamos ante un nombre atestiguado. Pero proponer una enmienda a una hipotética abreviatura resulta obviamente atrevido).

De mantener pues la hipótesis antroponímica habría que proponer un nombre personal fenicio no atestiguado, algo teóricamente posible en este caso partiendo de elementos conocidos, pero siem- 
pre hipotético. [A modo de ejemplo de las posibilidades teóricas: para los dos primeros grafemas se podría pensar, tomándolos directamente como consecutivos, en los teónimos ' $n$ o ' $n t$ o, si se debiera buscar un elemento verbal, en el conocido -también en hebreo-, ' $n n$ (véase de nuevo Benz 1972: 380 y 382), combinados respectivamente con elementos verbales / nominales que contengan $\check{s}$ o $k$, o con teónimos que presenten igualmente dichas consonantes (solo los que iniciarían con $\breve{s}$ son ya abundantes y no faltan de inicial $k$, Benz 1972: 330-336, 412-427) pero siempre con el problema de la escasa base sobre la que defender nuevas combinaciones]. También es siempre posible suponer directamente un nombre del todo desconocido (y quizá pues no fenicio, aunque cualquiera de las lecturas sugiere una fonética semítica o muy próxima al semítico) siempre al precio de adentrarse por un camino progresivamente más y más incierto.

Por ello, conviene en este caso considerar también una opción menos habitual, pero posible: que el término sobre el cuenco no fuera una marca de propiedad, sino un término común con otra función. Por un lado, la lectura ' $n k$ no parece responder directamente a un vocablo fenicio. Se podría recurrir a una segmentación morfológica que diera sentido a la secuencia. [Sólo por señalar la posibilidad más obvia (pero no la única), $-k$ podría corresponder a un pronombre o adjetivo sufijado, pues no faltan posibilidades, incluso directas, para interpretar ' $n$ como sustantivo o forma verbal (véase alguna de estas posibilidades más adelante)]. Sin embargo, la opción resultaría muy poco probable en un grafito sobre recipiente cerámico. Del mismo modo, buscar una explicación etimológica dentro del semítico sin apoyos epigráficos resultaría demasiado especulativo. En cambio, por otro lado, un término ' $n s ̌$ sí está atestiguado en la epigrafía fenicia. Aparece como forma verbal en inscripciones púnicas y neopúnicas (vid. referencias en Hoftijzer y Jongeling 1995: 877-878) con el sentido básico de multar o recaudar una multa, impuesto o contribución (sentido bien conocido en el semítico noroccidental (vid. para el hebreo bíblico p. ej. Köhler y Baumgartner 1958: 722; en epigrafía, de nuevo Hoftijzer y Jongeling 1995: 877-878). Y es precisamente al producto de la exacción o colecta al que remite en último término su significación cuando aparece como sustantivo (recuérdese la famosa inscripción tripolitana de las termas adrianeas, KAI 130, en el que el sentido de la doble aparición de ' $n s ̌$ descansa ya principalmente en la suma o pago; vid. p. ej. la lectura e interpretación del propio Donner y Röllig 1974: 25, 133-134). Como en el grafito de Gorham el término, aislado, podría con más probabilidad corresponder a una forma sustantiva o sustantivada, habría que entender que define al objeto o a su contenido como una contribución o contrapartida que, en el contexto del santuario, podría corresponder a una ofrenda.

El término ' $n s ̌$ fue leído también en otra pieza peninsular, uno de los colmillos de marfil inscritos hallados en el yacimiento submarino del Bajo de la Campana (Sanmartín 1986: 89-103, n. 1.1.3: 90). $\mathrm{Su}$ editor entendía que podía tratarse del adjetivo "humilde", explicado a través de una base cuyo mejor testimonio semítico noroccidental sería el ugarítico ǵnt, "humillar(se)" (vid. ahora sin embargo Olmo y Sanmartín 2004: 323, sin mención de ǵnt; véase también Idem 2004: 172, ' $n w$, G: "to be / remain depressed, humbled"; D: "to humiliate, knock down"); el adjetivo habría sido usado en aquel epígrafe a modo de fórmula de salutación, de respeto. Sin embargo, la lectura de la inscripción del Bajo de la Campana parece ser otra y la interpretación del término ' $n s ̌$ dada por Sanmartín presenta muchas dudas (vid. más allá de lo dicho p. ej. Hoftijzer y Jongeling 1995: 878, s. v.: "highly uncert. interpret."). [En un examen reciente de la inscripción en el museo ARQVA de Cartagena hemos podido comprobar que ésta es más larga de cuanto se pensaba y que la hipotética secuencia 'nš no cierra la inscripción. La presunta $\breve{s}$ es en realidad un aleph interrumpido por un amplio daño superficial en la superficie del colmillo, mientras que el 'podría también ser una beth].

Aunque un sentido cercano a la humillación, en uso votivo (¿como autocalificación del oferente?) podría tener todavía respaldo etimológico [ya fuera leyendo ' $n s ̌$ y aceptando una etimología como la propuesta por Sanmartín o leyendo ' $n k$, que podría siempre tomarse por un sustantivo sufijado con sentido adecuado a este uso, vid. p. ej. el ugarítico " $n n$, "manservant, servant", Olmo y Sanmartín 2004: 170; nótese en cualquier caso la ausencia de preposición introductoria] y encajar en el contexto cultual del santuario de la cueva de Gorham, lo cierto es que se trata de una alternativa problemática.

Así pues, al grupo de posibilidades que llevarían a comprender bajo el epígrafe hallado en la gruta un marcado de propiedad o similar (función propia de este tipo de grafitos breves) se unen otras que permitirían interpretarlo como una breve inscripción de naturaleza votiva (más excepcional). Parecería que, entre unas y otras opciones, el contexto de hallazgo en cueva santuario, privilegiaría a las segundas, pero no hay que olvidar que la pieza pudo recibir el epígrafe lejos del santuario y antes de que su destino fuera formar parte de una ofrenda. 


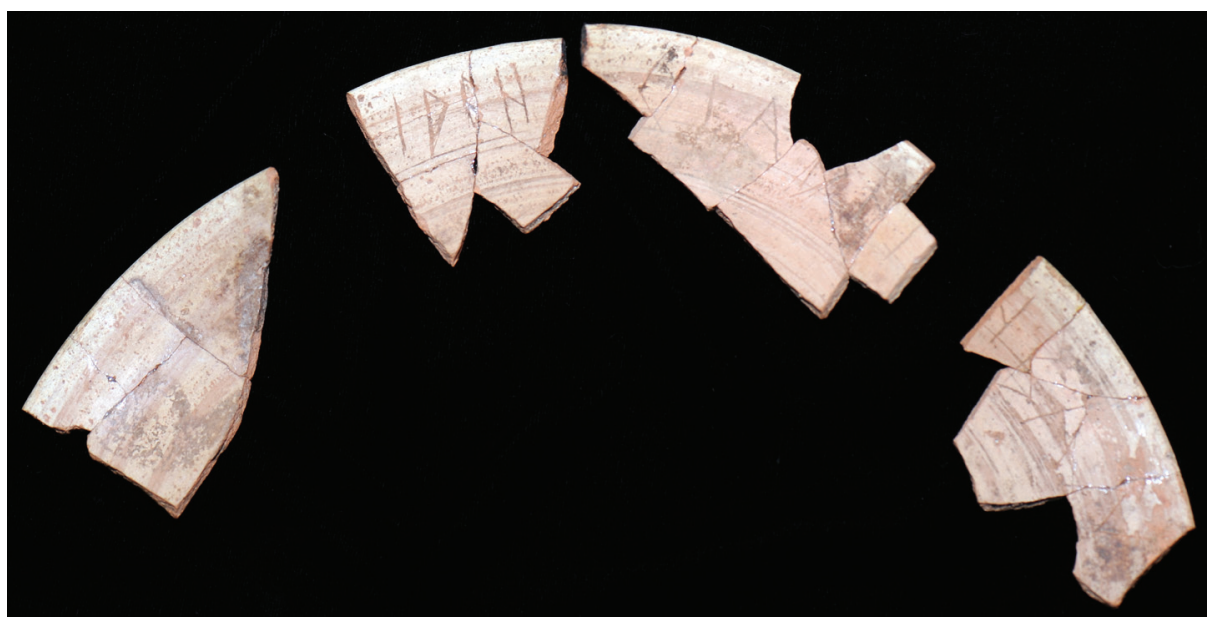

Fig. 5.- Fotografía de los fragmentos conservados de la pieza GOR-176.

\section{- Conclusión}

En definitiva, nos hallamos ante un breve grafito fenicio inciso sobre la pared de un recipiente cerámico que, como buena parte de estos testimonios, podría corresponder a un marcado de propiedad mediante nombre personal; en tal caso, el presunto antropónimo no sería conocido todavía dentro del fenicio. Ante esta dificultad, no puede descartarse enteramente que el grafito correspondiera al grabado de una indicación o expresión votiva (mediante un término de etimología relacionada con una tributación, pago o contribución, bien atestiguado en el semítico noroccidental y en la epigrafía fenicia, pero desconocido hasta ahora con uso cultual) si bien se trataría, de nuevo, de una inscripción sin paralelos (y por tanto dudosa).

Sea como fuere, las grafías remiten a un autor fenicio, como lo hace a través de ellas la lengua que parecen sostener, en vista de la fonética más probable que se deriva de su lectura y a la luz de las diferentes posibilidades antes apuntadas de interpretación del epígrafe en lengua fenicia.

5. 2. La segunda pieza con inscripción era tenida por un epígrafe en grafías ibéricas. De este modo fue mencionada (y presentada mediante un primer dibujo facilitado por el equipo de la excavación) en publicaciones previas a su estudio (Gutiérrez et al. 2001a: 18; García y Martín 2010: 265, fig. 3 ). Se trata de un cuenco de cerámica común (Sigla GOR-176) originario de la costa mediterránea andaluza o de la bahía de Algeciras y datable en el periodo de frecuentación de la cueva definido convencionalmente como púnico, probablemente entre los s. IV a.C. y II a.C. Se conserva en múl- tiples fragmentos de borde y cuerpo, que permiten reconstruir la pieza [sus dimensiones son: $\mathrm{H}=$ $26 \mathrm{~mm}, \varnothing=$ borde (reconstruible) $170 \mathrm{~mm}, \mathrm{E}=$ $04 \mathrm{~mm}$ ] y apreciar que se trata de una forma muy abierta. El borde de la pieza es exvasado, con labio redondeado simple no diferenciado. La pasta cerámica es rojiza, con partículas de cuarzo sin aristas, algo de material calcáreo, puntos de arenas negras y grises (¿esquistos?) y algún granate. La superficie cerámica recibió un engobe blanquecino, que se conserva mejor en el interior del cuenco. Los restos de recipientes de producción común con este tratamiento, todos ellos abiertos, forman entre los hallazgos del santuario una serie muy característica.

Los múltiples fragmentos conservados pueden agruparse en 4 piezas de mayor tamaño (fig. 5). Tres de ellas presentan signos que son claros grafemas. Se hallan incisos post-cocción en la superficie interior del cuenco, cercanos al borde. Dos de los fragmentos, con cuatro y seis letras respectivamente, pueden unirse a su vez entre sí (quedando un pequeño vacío intermedio a la altura de los signos, que no parece sin embargo ocultar grafema alguno) proporcionando la más larga de las secuencias conservadas. Cuatro signos más forman la secuencia menor, sin continuidad con la anterior. El fragmento anepígrafo prueba que el texto no recorría todo el borde del cuenco, aunque la distancia reconstruible entre los fragmentos inscritos sugiere un texto largo (fig. 6; partiendo de la posición reconstruida de los fragmentos, entre las dos series conservadas, de 10 y 4 letras respectivamente, habría espacio para entre 5 y 9 grafemas más -dependiendo de si los signos eran parecidos en tamaño a la secuencia de grafemas más pequeños, o a aquella de grafemas más grandes-siempre y cuando el texto fuera continuo). 


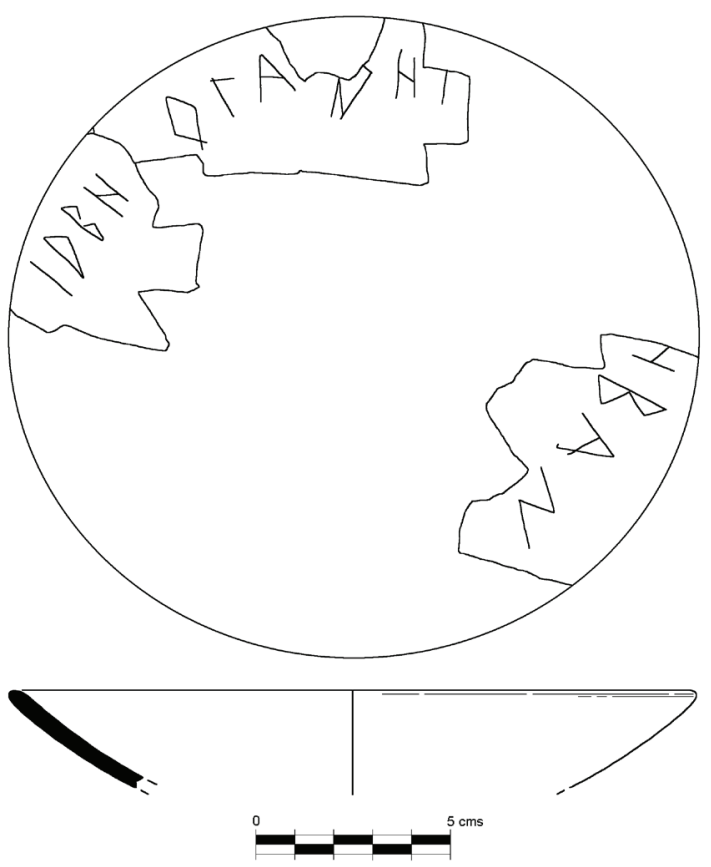

Fig. 6.- Dibujo arqueológico de la pieza GOR-176.

Los grafemas del epígrafe se asemejan a signos griegos de tipo Jonio, con la particularidad de que todos cuantos aparecen corresponden a los usados en las llamadas "inscripciones greco-ibéricas" (textos en lengua ibérica consignados en un sistema gráfico adaptado del griego, véase p. ej. Hoz 1987 ; 2001; 2010) guardando el elenco presente en GOR-176 gran parecido con algunos de los testimonios grecoibéricos más característicos y conocidos, como el famoso plomo largo de La Serreta de Alcoy (vid. p. ej. Untermann 1990: 564-568, G.1.1). La nueva inscripción parece ser en efecto un nuevo documento greco-ibérico, un hallazgo excepcional que no sólo ampliaría los testimonios de estas no muy numerosas inscripciones, sino que agrandaría en mucho su área de hallazgo. Ésta se restringía hasta ahora casi exclusivamente a una reducida zona del Levante peninsular (hoy repartida entre las provincias de Murcia y Alicante) lo que convierte al hallazgo de Gorham en un ejemplo lejano y aislado de tal núcleo. Por otra parte, la cronología de las inscripciones hasta hoy conocidas (que al parecer se dan en contextos arqueológicos mayoritariamente del s. -IV a.C., con algunos testimonios alargando quizá el intervalo desde finales del s. $-\mathrm{V}$ a principios del -III a.C.) está dentro de la datación asignable a la nueva pieza en la cueva gibraltareña (pudiendo por tanto el epígrafe contribuir a la mejor datación de su soporte).

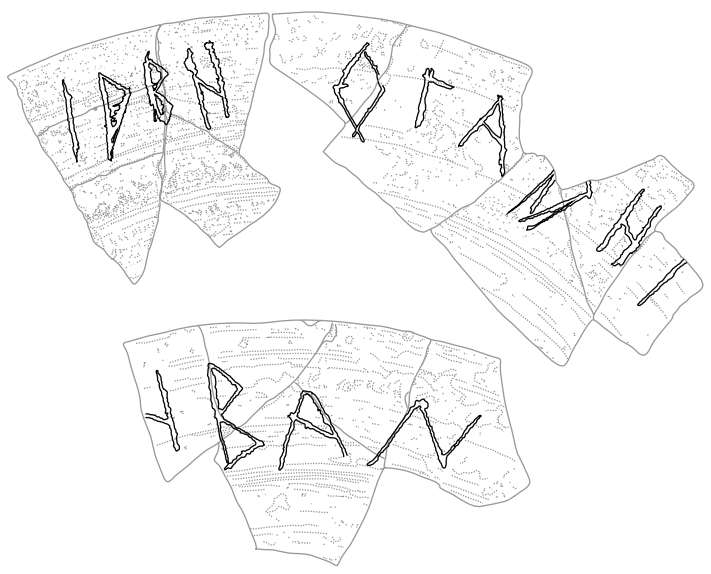

Fig. 7.- Dibujo epigráfico de los signos greco-ibéricos incisos en la pieza GOR-176.

En signario greco-ibérico, la lectura del grafito sería a nuestro juicio IRBE OGAREI[ ... ] EBAN (lo que parece confirmar la naturaleza ibérica de la lengua del grafito). En cualquier caso, el estudio de la inscripción deberá ser acometido por los especialistas en este tipo de textos ${ }^{2}$, contentándonos aquí con presentar, además de la foto y dibujo arqueológico de la pieza (figs. 5-6), un dibujo epigráfico de la inscripción (fig. 7).

Serán pues los especialistas en epigrafía ibérica los que podrán proporcionar más información sobre la naturaleza del texto y sus implicaciones. Sin contar con esos futuros datos, partiendo sólo de la mera apariencia del epígrafe, sólo pueden adelantarse hipótesis. Obvio es proponer para el documento, a la luz del contexto cultual del hallazgo y de las características del texto (trazado con tamaño y holgura sobre una parte bien visible de la superficie de uso del recipiente) una función votiva. Pero no hay que olvidar que el objeto pudo recibir la inscripción (como se decía para el grafito fenicio anterior) con anterioridad a su llegada a la cueva e incluso con anterioridad a asumir su definitiva función como parte de una ofrenda.

A este respecto, es siempre posible proponer que la zona de incisión del cuenco fuera, a pesar de todo, la principal hasta hoy conocida en la utilización del alfabeto greco-ibérico (posibilidad que cobraría relieve añadido si los especialistas en lengua ibérica establecen que el texto no es con claridad votivo). En tal caso, la aparición meridional del nuevo testimonio no supondría necesariamente una mayor extensión del área de uso regular de esta combinación de lengua y sistema gráfico sino que, por el contrario, la concentración de testimonios atestiguada hasta el momento podría apuntar a una realización 
de la inscripción en el área murciano-alicantina. Sin embargo, el soporte de la inscripción (que, como se decía, es parte de una serie de recipientes bien identificada en la cueva) podría haber sido fabricado en algún lugar de la costa mediterránea andaluza o de la bahía de Algeciras. Aunque este dato deberá ser confirmado por los estudios en curso de caracterización de pastas cerámicas, hay indicios que apuntan a una fabricación de la pieza quizá más cerca de su lugar de amortización que de la zona nuclear de atestiguación del conjunto greco-ibérico. De confirmarse, no resultaría probable que el cuenco hubiera sido fabricado en la costa andaluza, inscrito más al norte y depositado de nuevo al sur... junto a otros recipientes de su mismo tipo. Más bien parecería que el cuenco, como los demás de su serie, hubiera circulado como mucho por su zona de fabricación para, en un uso final, acabar depositado en el santuario. Si tal fue el caso, debió recibir la inscripción en algún momento de esta vida meridional (quizá, después de todo, en el momento de su deposición) y por lo tanto fuera de la zona hasta hoy atestiguada para este tipo de textos (aunque por mano de un buen conocedor de una tradición escrita que se manifiesta aún mayoritariamente en tal zona). Estudios futuros podrán arrojar más luz sobre el argumento.

Parece innegable, en cualquier caso, la existencia de un vector, local o externo, que relacionaba ámbitos culturalmente diversos y probablemente distantes dentro de una intensa actividad que debió ser ante todo comercial. Este hecho, que se refleja en el registro material de la Cueva de Gorham subrayando su cosmopolitismo, podrá quizá ayudar a la mejor comprensión del peculiar origen y uso de la propia escritura greco-ibérica.

\section{Marcas no grafemáticas}

6. 1. El documento más arcaico (Sigla GOR-115, fondo antiguo $\mathrm{GC} / \mathrm{W} 87 \mathrm{a}-\mathrm{j}$ ) era en origen un cuenco carenado de barniz rojo procedente de la Fenicia Oriental, conservado hoy en diversos fragmentos correspondientes a su borde y cuerpo (fig. 8, a-b; sus dimensiones: $\mathrm{H}=58, \varnothing=180, \mathrm{E}=055 / 065$ $\mathrm{mm})$. El borde de labio es ligeramente triangular, caído al exterior. En la pared presenta una acanaladura que separa prácticamente el borde del cuerpo. Éste tiene tendencia troncocónica y una sueva carena que da paso a la base. La superficie presenta barniz rojo de tonalidad marrón clara, total al interior y sólo bajo la carena al exterior, es denso, compacto y de tacto suave. La pasta es ocre-grisácea, de textura compacta y rotura irregular con tacto jabonoso, y la cocción oxidante completa. Los desgrasantes son casi inapreciables, sólo se observa mica. Cabría la

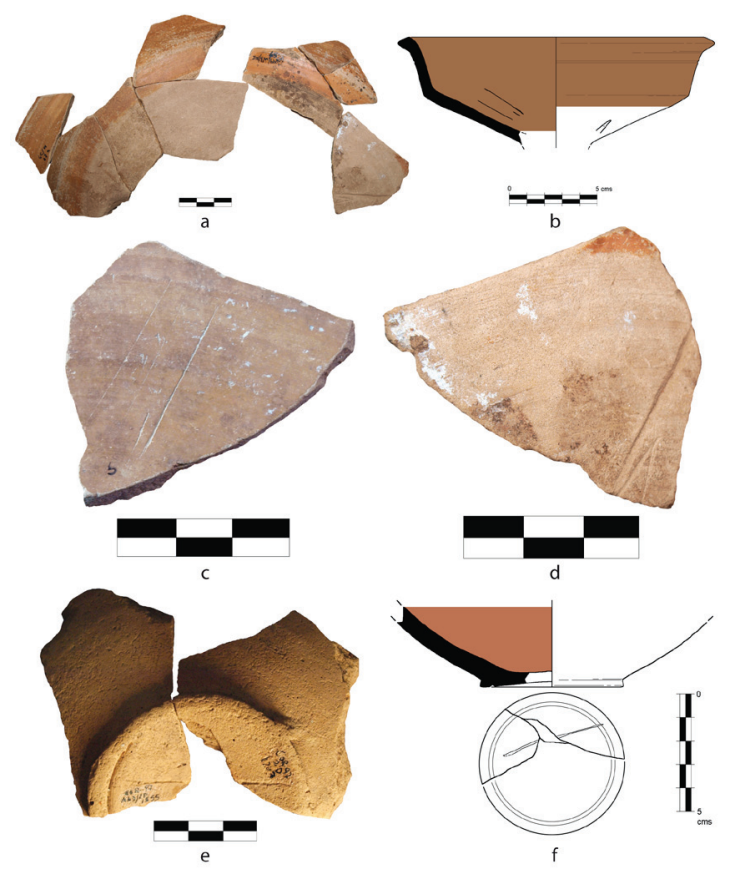

Fig. 8.- a-b: Fotografía y dibujo arqueológico de la pieza GOR-115; c-d: Fotografía del fragmento de la pieza GOR-115 con marcas incisas; e-f: Fotografía y dibujo arqueológico de la pieza GOR-137.

posibilidad de interpretar la pieza como parte de un quemaperfumes de doble recipiente, pero la ausencia de indicios en este sentido ha llevado a optar por una atribución provisional menos comprometida y definirla como cuenco. Se dataría en los ss. -IX-VIII a.C.

Entre los fragmentos se han reconocido incisiones realizadas postcocción. Hasta 4 líneas más o menos paralelas ( 1 corta y 3 largas son claramente visibles, 2 de estas últimas muy finas) se advierten en su parte interior (fig. 8c); ninguna es claramente interrumpida por las roturas, aunque no es imposible que hubieran sido realizadas en el interior de la pieza antes de su rotura. No es obvia en cualquier caso su intencionalidad y no se agrupan formando signos. En cambio, en la cara externa de uno de los fragmentos se aprecia una larga línea, profunda e interrumpida por los bordes rotos del fragmento; al lado de esta línea se observa el extremo de dos más (igualmente interrumpidas por una de las aristas) que se unen formando un ángulo; entre ellas, un pequeño trazo (poco claro) podría dibujar con las anteriores una forma más compleja (fig. 8d). Aunque no es evidente si este conjunto de líneas formaba un signo (tanto menos un grafema) es clara la intencionalidad de, al menos, los trazos en ángulo (trazos cuya longitud total no conocemos). Pudieron pues 
ser parte de una marca no grafemática, que se habría situado en la zona exterior (inferior) del cuenco, pero ya en su pared. Esta posición, junto con el tipo de incisión, hace más probable que fuera realizada por el propietario, y no por el alfarero o comerciante, si es que en efecto se trato de una marca.

6. 2. Otro documento de la fase arcaica, aunque sin mayor precisión cronológica, es el correspondiente a un fragmento de cerámica de barniz rojo (sigla GOR-137), identificado como una producción occidental indeterminada (fig. 8, e-f). Pertenece a la base del cuenco (una forma profunda) con pie marcado al exterior, ligeramente triangular, con anillo solero en el fondo y tendencia a ser cóncavo (sus dimensiones son: $\mathrm{H}=25, \varnothing=$ base $60, \mathrm{E}=045 / 07$ $\mathrm{mm}$ ). La pasta es de color anaranjado y aspecto laminado, con desgrasantes finos de cal, mica, granos de cuarzo y partículas rojo-granates. En la superficie interior se aprecia el engobe rojo, muy perdido.

Presenta en el exterior de la base al menos una línea incisa post-cocción. Aunque interrumpida por las roturas, se advierte que atravesaba de un lado a otro el círculo de la base, siendo muy probable que una segunda línea perpendicular perdida (de la que sin embargo no quedan trazas donde podrían ser visibles) formara con ella una gran aspa. Sea como fuere, se trata de una marca no grafemática que, por su posición, podría corresponder a una marca de alfar (realizada en cualquier caso tras el secado/horneado de la pieza) o de comercio, destinada a distinguir de manera sencilla el recipiente o el lote de recipientes que lo acompañaban.

6. 3. Un tercer documento de cronología arcaica es un plato de borde estrecho de cerámica de barniz rojo (GOR-053) conservado en varios fragmentos que permiten reconstruir de modo casi íntegro su forma (fig. 9, a-b). Se trataría, más precisamente, de un plato de borde estrecho con pequeño escalón debajo, cuerpo hemiesférico y base de pie marcado con tendencia cóncava del fondo $(\mathrm{H}=50, \varnothing$ $=$ borde $200 /$ base $58, \mathrm{E}=05 \mathrm{~mm}$ ). Su pasta es de fractura irregular, con nervio de cocción muy poco apreciable, gris al interior y ocre-anaranjado al exterior, que presenta vacuolas y abundante desgrasante cuarcítico, mica y arenas. Las superficies exteriores se presentan alisadas, al interior con un engobe denso de tono anaranjado y evidencias de ennegrecido en el fondo. Es una producción de la costa mediterránea andaluza datable en los siglos IX/-VIII a.C., atribuible al Horizonte B1 de Morro de Mezquitilla.

De nuevo en la base exterior (apenas conservada) se aprecia el final de un trazo inciso sobre la

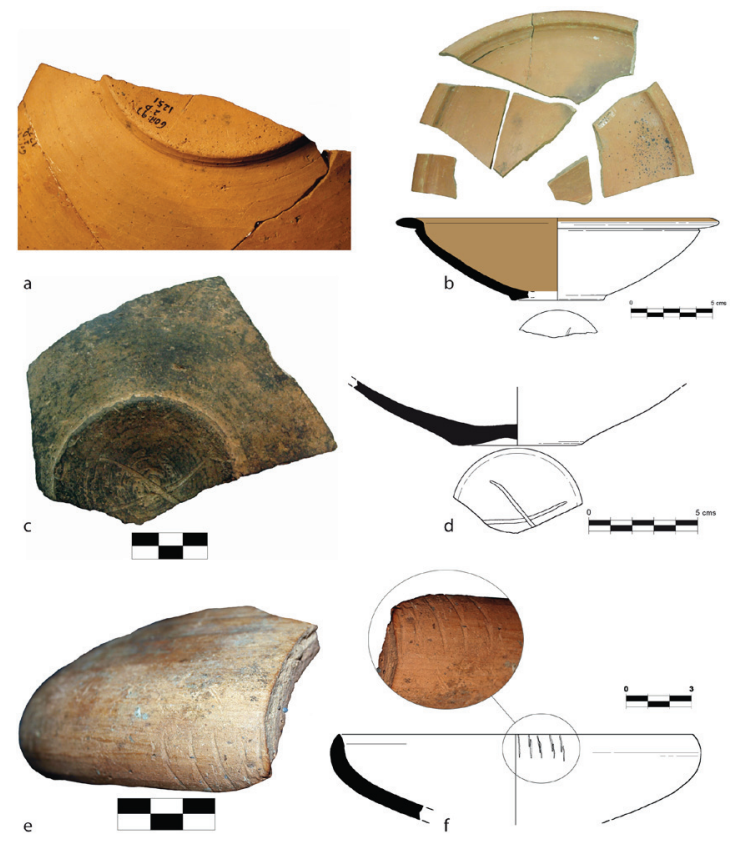

Fig. 9.- a-b: Fotografía y dibujo arqueológico de la pieza GOR-053; c-d: Fotografía y dibujo arqueológico de la pieza GOR-019; e-f: Fotografía y dibujo arqueológico de la pieza GOR-332 (con detalle fotográfico de las incisiones).

cerámica ya dura. A diferencia de los documentos anteriores, en éste la línea fue trazada con limpieza y definición. Es imposible saber si era parte de un signo complejo (incluso de un grafema) aunque la continuación sutil de la línea más allá de su incisión principal hace pensar en un gesto largo, parte del trazado de un gran signo, quizá simple. Podría pues tratarse de una marca de alfar o, en vista de su factura postcocción, comercial.

6. 4. Otra pieza de cronología arcaica es parte de un plato de cerámica gris (sigla GOR-019, fondo antiguo GB5) de atribución occidental indeterminada (fig. 9, c-d). El fragmento (con dimensiones $\mathrm{H}$ $=25 ; \varnothing=$ base $60 ; \mathrm{E}=05 / 110 \mathrm{~mm})$, que corresponde a la base apenas marcada del pie, presenta al interior omphalos central, marcado desde el exterior. La pasta es gris, con abundantes partículas calizas como desgrasante. Las superficies exteriores se conservan deficientemente, aunque se observan indicios de espatulado sobre el torno con un instrumento estrecho y romo.

En la parte correspondiente al fondo exterior del plato se observan los restos de lo que debió ser un aspa, incisa sobre la arcilla aún fresca. Se trata pues, con seguridad, de una marca realizada en el 


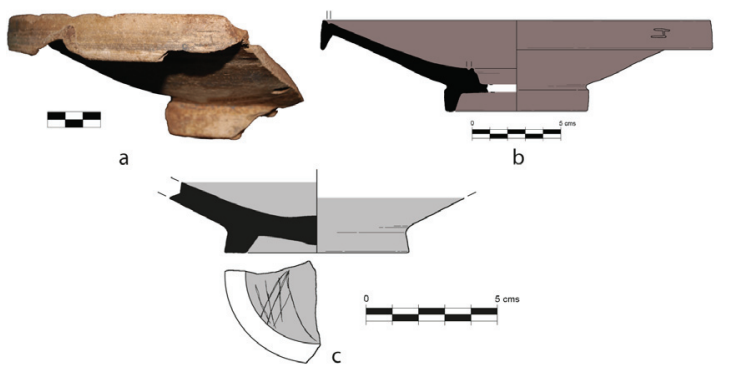

Fig. 10.- a-b: Fotografía y dibujo arqueológico de la pieza GOR-140; c: Dibujo arqueológico de la pieza GOR-099.

alfar durante la producción de la pieza, que pudo estar destinada a marcar ésta dentro de sus fases de elaboración, a distinguirla según su destino, o a individuarla con otros propósitos siempre difíciles de probar.

6. 5. De cronología en cambio posterior, (fase clásico-helenística) es un fragmento de cuenco de cerámica común (sigla GOR-332, dimensiones: $\mathrm{H}=$ $38, \varnothing=$ borde $160, \mathrm{E}=07 \mathrm{~mm})$, producción de la costa mediterránea andaluza (fig. 9, e-f). Conserva parte del borde que es entrante con labio apuntado, ligeramente triangular y marcado al interior del cuerpo, con tendencia hemiesférica y suaves ondulaciones en la zona inferior. La pasta es anaranjada sonrosada, compacta con distribución irregular del desgrasante que se compone de partículas cuarcíticas redondeadas, puntos rojos y láminas de esquisto o pizarra con algo de mica. Las superficies se presentan alisadas.

Al exterior, muestra sobre el borde 5 cortas líneas transversales, realizadas todas postcocción, que se configuran a intervalos regulares. No se trata del producto de un accidente de excavación, pero tampoco de un intento de trazado de signos o formas complejas; su posición tampoco es la común en las marcas y no es ni siquiera clara su intencionalidad. La pauta regular bien pudo obedecer al roce, intencionado o no, con un objeto, incluso una herramienta, durante su uso o amortización antiguos.

6. 6. Una de las piezas más recientes (sigla GOR140) es un fragmento de plato de pescado forma L-23, de cerámica de barniz rojo helenístico tipo Niveau-II (2003: 46-55). Sus dimensiones son: H $=50, \varnothing=$ borde $220 /$ base $07, \mathrm{E}=06 / 07 / 11 \mathrm{~mm}$. Se conserva el perfil completo (fig. 10, a-b), que presenta un borde de labio ancho, ligeramente triangular y colgante, con una fina acanaladura al interior; paredes rectas divergentes formando un cuerpo troncocónico abierto, separado de la base por una inflexión ligeramente angulosa que da lugar a un alto pie de sección cuadrangular. El interior del recipiente presenta una acanaladura y moldura que distinguen el pocillo, que se estrecha en profundidad progresivamente. La pasta es ocre-amarillenta, con desgrasante fino calizo, alguna mica y arena, llegando a mostrar grandes vacuolas al exterior. Ambas superficies muestran un engobe marronáceo prácticamente negro que se aplicó por inmersión, como dejan deducir los indicios existentes en el exterior. Se atribuye a una producción de tipo Kouass fabricada en la Bahía de Cádiz en la fase plena de producción de estas formas (Sáez 2008: 326-328), entre la segunda mitad del siglo III a.C. y los inicios del siglo II a.C.

En la banda exterior del labio se aprecian al menos tres cortas incisiones, combinándose en lo que parece un signo. [Aunque las dos líneas más largas, paralelas entre sí y al propio borde, siguen las líneas del torno, parecen claramente intencionadas. También la línea transversal que las une es una incisión consciente, existiendo además otras dos posibles líneas perpendiculares añadidas, más sutiles e inseguras, que completarían así un signo en forma de escalera, muy común en casi cualquier periodo como marca]. De todas las marcas de Gorham que agrupamos como no grafemáticas, sólo esta última podría corresponder aún a una letra fenicia, una heth, a tenor además de que la distribución de las líneas podría dar una morfología paleográficamente adecuada. Pero las dudas sobre algunas de las incisiones y el esquematismo general del signo, nos lleva a ser cautos. Se trataría en cualquier caso de una marca que, por su posición, podría corresponder a una probable indicación de propiedad, que de aceptar su naturaleza grafemática (y fenicio-púnica, extremo éste que no agota las posibilidades de identificación de la marca como escritura) podría ser la abreviatura de uno de los muchos antropónimos fenicios de $h$ - inicial (Benz 1972: 306 y ss).

6. 7. La pieza más reciente del conjunto (sigla GOR-099, Alex. Coll. GR/A-3) se encontraba en el Gibraltar Museum entre un conjunto de elementos procedentes de Gorham reunidos bajo la denominación de Colección Alexander (Alex. Coll) por lo que podría pertenecer a los trabajos desarrollados por los ingenieros militares Alexander y Monke en el tramo interior de la galería en los años 40 del siglo pasado (Gutiérrez et al. 2013: 308-309). Es un fragmento de cerámica de barniz negro, parte de un recipiente abierto Campaniense $\mathrm{A}$, posiblemente de la forma L-27, que puede datarse en el s. III a.C.. El fragmento corresponde a la base del recipiente y sus dimensiones son $\mathrm{H}=20 ; \varnothing=$ base $68 ; \mathrm{E}=$ 
08/10 mm. La pasta es anaranjada, con el barniz negro conservado deficientemente debido a las condiciones postdeposicionales en la cueva.

En el exterior de la base presenta una marca incisa post-cocción de múltiples trazos que, obviamente, no forman un grafema, pero que constituyen sin duda una marca compleja de producción o, más probablemente quizá, de comercio (fig. 10c).

\section{Conclusiones}

La cueva de Gorham resulta pues un ejemplo magnífico de lo que debió ser un tipo de lugar sacro más común de cuanto se pensaba en el Mediterráneo antiguo: la gruta-santuario costera, donde las prácticas atestiguadas, en forma de restos de frecuentación y ofrenda, debieron vincularse fuerte e indefectiblemente a las necesidades y creencias de los hombres de mar. La cueva gibraltareña es excepcional por su importancia antigua, reflejada en el registro arqueológico y acorde a su posición en la divisoria última entre el Mediterráneo y el Océano; y es excepcional por su utilidad a la investigación presente, dado el volumen de datos que aporta tanto para el conocimiento de este tipo de lugares como para la reconstrucción de la historia de esta zona extremo-occidental a través de quienes hicieron uso del santuario. Entre los materiales proporcionados por la Cueva de Gorham, los inscritos (pocos, pero muy interesantes y significativos) permiten adentrarse un poco más en la caracterización de estos fieles que frecuentaron el lugar, puesto que añaden informaciones relacionadas de forma explícita con sus ámbitos culturales. Estas gentes son, a su vez, imagen representativa de las que transitaban las aguas del Estrecho -como lo son los bienes con los que se movían- y su variación en el tiempo (en creciente diversidad) va a verse reflejada en los materiales incisos de manera paralela a cómo lo hace en el conjunto del registro material del yacimiento.

En efecto, si en el periodo inicial y arcaico se atestiguan en la cueva materiales de origen fenicio oriental o cerámicas fenicias del mediterráneo andaluz, las tres marcas más antiguas van a aparecer sobre materiales fenicios procedentes, respectivamente, de Fenicia, de algún establecimiento fenicio occidental y de la costa mediterránea andaluza. Si hasta el s. -VI a.C. se van atestiguando materiales cada vez más variados, a esa misma centuria va a corresponder el cuenco greco-oriental con inscripción fenicia aparecido en la cueva. Si en esta época la variedad material se amplía (a producciones del área de Málaga, de Cartago, de centros fenicios insulares centromediterráneos, continentales del Occidente, de núcleos orientalizantes) una cuarta mar- ca se presenta entonces sobre una pieza de cerámica gris de producción occidental. Si la intensificación comercial y la consolidación del santuario en época púnica se muestra a través del incremento productivo del área de Cádiz y de la aparición de producciones ebusitanas, tingitanas, turdetanas y áticas, para después, bajo la influencia y enseguida hegemonía romana, pasar a ser protagonistas los materiales itálicos y las cerámicas ibéricas (junto a las últimas producciones helenísticas regionales), serán entonces materiales producidos en el Mediterráneo andaluz y en la Bahía de Cádiz los que aparecerán incisos, y se atestiguarán también en el yacimiento un cuenco con inscripción en lengua ibérica y una pieza campaniense marcada.

Pero los epígrafes y marcas del yacimiento no sólo pertenecen a fases muy variadas y se presentan sobre materiales muy diversos, como reflejo de la propia historia del santuario. También difieren en sus características técnicas (en su trazado, en su posición) algunas de ellas quizá en relación a su función: las incisiones más sencillas, situadas en los fondos de los recipientes, podrían ser marcas comerciales; alguna podría también corresponder a un marcado de alfar, como es seguro para la pieza incisa precocción; algunos de los recipientes podrían presentar, en sus paredes, marcas de propiedad. Todas estas posibles marcas, y quizá incluso los seguros epígrafes, pudieron realizarse antes de que las piezas cerámicas asumieran su papel votivo (reflejando pues prácticas propias del ámbito de procedencia o circulación de los materiales). Pero es también posible que alguna de las inscripciones propiamente dichas, o ambas, correspondieran a acciones votivas.

Estas dos inscripciones son en cualquier caso de diversa adscripción gráfica y lingüística: la más antigua presenta un vocablo, muy probablemente fenicio, escrito en grafía fenicia; la más reciente es un texto en lengua ibérica consignado en una escritura del levante peninsular que se sirve de grafemas griegos (el llamado alfabeto greco-ibérico). Pertenecen por tanto a ámbitos culturales bien diversos. El primero reflejaría bien la identidad fenicia que se supone a los primeros frecuentadores del santuario (o, si se quiere enunciar de modo más cauto, reflejaría al menos el ambiente cultural fenicio en el que se moverían buena parte de ellos). La segunda, mostraría la importancia de otro tipo de gentes, quizá iberos del Levante peninsular, o reflejaría la extensión de su cultura (aunque parece difícil que el cuenco inscrito no fuera ofrendado en la cueva por fieles llegados o relacionados en último término con la zona ibérica). De forma particular, se subrayaría así la importancia en época avanzada del elemento ibérico (especialmente si el texto del cuenco resul- 
tara ser un epígrafe votivo específicamente redactado para la ofrenda en la cueva, pero igualmente si no). De modo general, se apreciaría el creciente "cosmopolitismo" alcanzado por un santuario de la naturaleza del de Gorham.

Este "cosmopolitismo", comprensible a la luz de la intensificación de contactos e intercambios que antes se exponía, puede entenderse como el resultado de inserciones novedosas en un contexto de raíz y continuidad semítica (un paradigma muchas veces aplicado por defecto a las áreas peninsulares de antigua presencia colonial). Sin embargo, trascendiendo la mera dicotomía fenicios - no fenicios, la creciente variedad material presente en el santuario y la correspondiente heterogeneidad que supone en la adscripción cultural de sus fieles podría entenderse también como simple fruto de la rica historia cultural del lugar sacro. Su carácter sería, en cada momento, un resultado histórico complejo que aunaba elementos que somos capaces de percibir, aislar e identificar, pero que, lejos de corresponder a formas culturales igual de definidas (sobre las que proyectamos como resultado cierta compartimentación e inmovilismo) debieron pertenecer a realidades en constante interacción y cambio (incluidas aquellas que percibimos bajo la categoría de la continuidad).

A este respecto, debe además tenerse en cuenta la especial naturaleza de un santuario como el de la cueva de Gorham. Éste no debe ser necesariamente contemplado bajo el prisma que, de nuevo casi por defecto, aplicamos a cierto modelo templario antiguo, entendido como un lugar sacro bien definido, caracterizado por un culto regular y regido por un clero que lo caracteriza, preservando su tradición (esto es: las creencias y prácticas que le dan continuidad). La especial naturaleza de la cueva-santuario pudo hacer que tanto las prácticas como las creencias a ellas ligadas descansaran ante todo en los fieles quienes, a su vez, constituían por tanto el elemento principal de caracterización del lugar. La adscripción cultural crecientemente variada de los oferentes y frecuentadores de Gorham obliga a pensar en un ámbito de culto cuya naturaleza se define propiamente por la nueva variedad o por la nueva síntesis que produce y no, simplemente, por el añadido o aceptación de nuevos elementos en formas de culto troncal o esencialmente semíticas, si es que lo fueron en origen.

\section{Notas}

1. El trabajo epigráfico se enmarca en el proyecto "Estudio y edición de inscripciones fenicias y púnicas de la Península Ibérica inéditas o mal conocidas y publicación del corpus de epígrafes peninsulares" (FFI2010-17342) del Plan Nacional de I+D+I del Ministerio español de Ciencia, Investigación e Innovación. La investigación arqueológica cuenta con el soporte permanente del Gobierno de Gibraltar y puntualmente se ha insertado en acciones promovidas desde la Unión Europea (EU Interreg IIIB MEDOC Programme: 2002-02-4.1-U-048).

2. El estudio especializado y la edición de la pieza correrá a cargo de los prof. F. Beltrán y J. Velaza, quienes amablemente nos han confirmado la naturaleza greco-ibérica de la pieza (como también, con el artículo ya entregado, el prof. De Hoz, a quien agradecemos así mismo su amabilidad).

\section{ReFERENCIAS Bibliograficas}

Antonelli, L. (1997): I Greci oltre Gibilterra. Rappresentazioni metiche dell'estremo Occidente e navigazioni commerciali nello spazio atlantico fra VIII e IV secolo a. C. Hesperia 8, Roma.

Belén DeAmos, $M^{a}$. (2000): Itinerarios arqueológicos por la geografía sagrada del extremo Occidente. Santuarios fenicio-púnicos en Iberia y su influencia en los cultos indígenas. XIV Jornadas de Arqueología Fenicio-Púnica (B. Costa y J. H. Fernández, eds.), Eivissa: 57-102.

BeléN, Má; Pérez, I. (2000): Gorham's Cave, un santuario en el Estrecho. Avance del estudio de los materiales cerámicos. Actas del IV Congreso Internacional de Estudios Fenicios y Púnicos, II (M. Barthelemy y M. E. Aubet, eds.), Cádiz: 531-542.

Benz, F. L. (1972): Personal names in the Phoenician and Punic Inscriptions. A Catalog, grammatical study and glossary of elements. Studia Pohl 8, Roma.

Berger, H. (1964): Die Geographischen Fragmente des Eratosthenes. Ámsterdam.

Bernal, D.; Arévalo, A.; SÁez, A. M. (2007): Nuevas evidencias de la ocupación en época republicana (ss. II-I a. C.). Las cetariae de Baelo Claudia. Avance de las investigaciones arqueológicas en el barrio meridional, 2000-2004. (A. Arévalo y D. Bernal, ed.). Salamanca: 237-353. 
Bernal, D.; Cottica, D.; SÁez, A. M.; Bustamante, M.; Toniolo, A. (en prensa): Ánforas ebusitanas y comercio en Pompeya (ss. III-I a.C.). Las evidencias del proyecto Impianto Elettrico (1980-1981) en el entorno del foro. EBUSUS e POMPEI, Testimonianze monetali di una relazione (Roma 12-13 noviembre 2010), EEHAR.

BoArdman, J. (1984): Escarabeos de piedra procedentes de Ibiza. Ministerio de Cultura, Madrid.

BRIDOux, V. (2008): Importations méditerranéennes du IIe s. av. n. è. en Maurétanie Occidentale et hypothèses sur les voies d'acheminement. Comercio, redistribución y fondeaderos. La navegación a vela en el Mediterráneo, Actas de las V Jornadas Internacionales de Arqueología Subacuática (J. Pérez Ballester y G. Pascual, eds.), Valencia: 425-434.

Снавот, J. В. (1945): Essai sur le système d'abreviation usité dans l'écriture phénicienne. Bulletin Archéologique du Comité des Travaux Historiques et Scientifiques 1943-45. Paris: 217-224 y 237-244.

Culican, W. (1972): Phoenician remains from Gibraltar. Australian Journal of Biblical Archaeology 1, $\mathrm{n}^{\circ}$ 5: 110 145 .

DonNer, H.; Röllig, W. (1974): Kanaanäische und Aramäische Inschriften, I-III (KAI). 1971-1974, 3ª ed. Wiesbaden.

El Khayari, A. (2004): Échanges entre le Maroc et la Méditerranée de l'époque phénicienne à l'époque tardorépublicaine. Meditérranée Occidentale Antique: les échanges (A. G. Zevi y R. Turchetti, eds.). Progetto ANSER (Anciennes Routes Maritimes Méditerranénnes), Rubbettino Editore. Roma: 149-168.

Ferrer Albelda, E. (2002a): Topografía sagrada del Extremo Occidente: santuarios, templos y lugares de culto en la Iberia púnica. Ex Oriente Lux: las religiones orientales antiguas en la Península Ibérica (E. Ferrer Albelda, ed.), Spal Monografías 2. Sevilla: 185-217.

Ferrer Albelda, E. (2002b): La religión púnica en Iberia: lugares de culto. El mundo púnico. Religión, antropología y cultura material (A. González, G. Matilla y A. Egea, eds.). Estudios Orientales 5-6, Murcia: $107-118$.

Finlayson, J. C. (1994): History of the Gibraltar excavations. Gibraltar during the Quaternary. AEQUA Monografias 2, Sevilla: 2-5.

Friedrich, J.; Röllig, W.; Amadasi Guzzo, M. G.; Mayer, W. R: (1999): Phönizisch-Punische Grammatik. Analecta Orientalia 55, Editrice Pontificio Istituto Biblico, Roma.

García Carretero, J. R.; Martín Ruiz, J. A. (2010): Grafito ibérico hallado en el Cerro del Castillo (Fuengirola, Málaga): nuevos datos sobre la presencia indígena en los yacimientos fenicios del Estrecho. Cuaternario y Arqueología. Homenaje a Francisco Giles Pacheco. Diputación de Cádiz. Cádiz: 263-269.

Gómez Bellard, C.; Vidal GonzÁlez, P. (2000): Las cuevas-santuario fenicio-púnicas y la navegación en el Mediterráneo. Santuarios fenicio-púnicos en Iberia y su influencia en los cultos indígenas. XIV Jornadas de Arqueología Fenicio-Púnica (B. Costa y J. H. Fernández, eds.). Eivissa: 103-145.

Gómez LucAs, D. (2002): Introducción al dios Bes: de Oriente a Occidente. Ex Oriente Lux: las religiones orientales antiguas en la Península Ibérica (E. Ferrer Albelda, ed.). Spal Monografías 2. Sevilla: 87-122.

GonzÁlez Ponce, F. J. (2008): A las puertas del abismo: la visión del Estrecho de Gibraltar en la periplografía griega. Territorios maritimos, comunicaciones, espacios naturales y humanos en la Bética costera (B. Mora Serrano, coord.), Mainake 30. Málaga: 59-74.

Gónzalez Wagner, C. (2008): Tiro, Melkart, Gadir y la conquista simbólica de los confines del mundo. Los Fenicios y el Atlántico (R. González Antón, F. López Pardo y V. Peña Romo, eds.), Centro de Estudios Fenicios y Púnicos. Madrid: 11-29.

Gorton, A. F. (1996): Egyptian and Egyptianizing Scarabs. A typology of steatite, faience and paste scarabs from Punic and other Mediterranean sites. Oxford University Committee for Archaeology. Monograph $\mathrm{n}^{\circ} 44$. Exeter.

Guirguis, M.; Enzo, S.; Piga, G. (2010): Scarabei dalla necropoli fenicia e punica di Monte Sirai. Studio cronotipologico e archeometrico dei reperti rinvenuti tra il 2005 e il 2007. International Journal of Archaeology Sardinia, Corsica et Baleares Antiquae VII: 101-116.

Gutiérrez, J. Ma.; Reinoso, Ma . C.; Giles, F.; Finlayson, J. C. (2001a): Nuevos estudios sobre el santuario de Gorham's Cave (Gibraltar). VI Jornadas de Historia del Campo de Gibraltar (Gibraltar 2000), Almoraima 25. Algeciras: 13-30.

Gutiérrez, J. Ma .; Reinoso, Ma . C.; Giles, F.; Finlayson, J. C.; Santiago, A. (2001b): Gorham (Gibraltar): una cueva santuario durante la Antigüedad. SEDECK, 2: 16-20. 
Gutiérrez, J. Ma .; Reinoso, Mª C.; Sáez, A. M.; Giles, F.; Finlayson, J. C. (2012): Las ofrendas de Hannón. El santuario de Gorham's Cave (Gibraltar) y la navegación cartaginesa atlántico-mediterránea. L'Africa Romana XIX, Sassari 2010. Roma: 2955-2970.

Gutiérrez, J. Ma ; Reinoso, Ma . C.; Giles, F.; Finlayson, J. C.; SÁez, A. M. (2013): La Cueva de Gorham (Gibraltar): un santuario fenicio en el confín occidental del Mediterráneo. Confines. El extremo del mundo durante la Antigüedad. (F. Prados, I. García y G. Bernard, eds.), Universidad de Alicante: 303-381.

Gutiérrez, J. Ma.; Reinoso, Mª C.; Giles, F.; Finlayson, J. C.; SÁez, A. M. (en prensa a): Données pour la définition de la phase archaïque du la Grotte de Gorham, Gibraltar. VIIème Congrès International des Études Phéniciennes et Puniques, Tunez-Hammamet 2009.

Gutiérrez, J. Mª; Reinoso, Ma . C.; SÁez, A. M.; Giles, F.; Finlayson, J. C.; Zamora, J. A. (en prensa B): El SANTUARIO de la Cueva de Gorham (Gibraltar): Estado de la cuestión (con la presentación de un nuevo grafito fenicio). Phéniciens d'Orient et d'Occident. Volume d'hommages dédié à Josette Elayi (A. Lemaire, ed.).

Hawkes, Ch. (1980): Gibraltar, Gorham's Cave: ibero-punic material with exotica (with contribution on the scarabs by John Boardman). IV Congreso Nacional de Arqueología (Faro, Portugal 1980), inédito.

Hoftijzer, J.; Jongeling, K. (1995): Dictionary of the North-West Semitic Inscriptions. Brill. Leiden / New York.

Hoz, J. DE (1987): La escritura greco-ibérica. Studia Palaeohispanica. Actas del IV Coloquio sobre lenguas y culturas paleohispánicas (J. Gorrochategui, J. L. Melena y J. Santos Yanguas, eds.), Veleia 2-3 (1985-1986), Vitoria: 285-298.

Hoz, J. DE (2001): La escritura greco-ibérica. Huellas Griegas en la Contestania Ibérica (M. Olcina Doménech y J. J. Ramón Sánchez, eds.), MARQ, Alicante: 30-132.

Hoz, J. DE (2010): L'écriture gréco-ibérique et l'influence hellène sur les usages de l'écriture en Hispanie et dans le sud de la France. Grecs et indigènes de la Catalogne à la Mer Noire-Actes des rencontres du programme européen Ramses² (2006-2008) (Bibliothèque d'Archéologie Méditerranéenne et Africaine - 3) (Henri Tréziny, éd.), Centre Camille-Jullian, Paris / Aix-en-Provence: 637-657.

KöHLER, L.; Baumgartner, W. (1958): Lexicon in Veteris Testamenti libros. Leiden

Lipiński, E. (1995): Dieux et déesses de l'univers phénicien et punique. Studia Phoenicia XIV. Louvain.

López de la Orden, Ma . D. (1990): La glíptica de la Antigüedad en Andalucía. Cádiz.

López de la Orden, Ma. D. (1990): Los escarabeos de Gorham's Cave: su iconografía. Actas del II Congreso Internacional 'El Estrecho de Gibraltar' (E. Ripoll Perelló y M. F. Ladero Quesada, eds.), II, UNED, Madrid: 119-127.

López Melero, R. (1988): El mito de las Columnas de Hércules y el Estrecho de Gibraltar. Actas del Congreso Internacional 'El Estrecho de Gibraltar (E. Ripoll Perelló, ed.), I. UNED, Madrid: 615-642.

López Pardo, F. (2000): El empeño de Heracles. La exploración del Atlántico en la Antigüedad. Arco Libros, Madrid.

Mancebo Dávalos, J. (1995): Cerro del Prado y el Estrecho de Gibraltar como zona receptora de influjos mediterráneos y transmisora hacia los poblados del interior en época orientalizante. Actas de las III Jornadas de Historia del Campo de Gibraltar (La Línea, octubre 1994), Almoraima 13. Algeciras: 83-86.

Marín Ceballos, Ma . C. (2010): Santuarios prerromanos de la costa atlántica andaluza. Debate en torno a la religiosidad protohistórica (T. Tortosa Rocamora y S. Celestino Pérez, eds.), Anejos de Archivo Español de Arqueología LV, Instituto de Arqueología de Mérida-CSIC, Madrid: 219-244.

Marín Ceballos, Ma . C. (2011): La singularidad religiosa de Gadir en el mundo fenicio-púnico. Cultos y ritos de la Gadir fenicia (M. C. Marín Ceballos, coord.). Servicio de Publicaciones Universidad de Cádiz: 535-558.

Martín Ruiz, J. A. (2007): La crisis del siglo VI a. C. en los asentamientos fenicios de Andalucía. Málaga.

Morel, J. P. (1988): Nouvelles donnes sur le commerce de Carthage punique. IV Colloque International sur l'Histoire et l'Archéologie de l'Afrique du Nord, I. Strasbourg : 67-100.

Moscati, S. (1987): Le officine di Tharros. Studia Punica 3, Roma.

Niveau de Villedary y Mariñas, A. Ma. (2003): Cerámicas gaditanas “tipo Kuass”. Bases para el análisis de la Bahía de Cádiz en época púnica. Bibliotheca Archaeologica Hispana 21. Real Academia de la Historia. Universidad de Cádiz. Madrid.

Olianas, C. (2009): Il diaspro verde in Sardegna. I giacimenti, le caratteristiche e il suo utilizzo nelle botteghe incisorie della Sardegna fenicio-punica. Atti del Convegno Nazionale dei Giovani Archeologi. Uomo e Territorio, dinamiche di frequentazione e di sfruttamento delle risorse naturali nell'antichità (M. G. Melis, ed.), Università degli Studi di Sassari. Muros: 363-369. 
Olmo, G. Del; Sanmartín, J. (2004): A Dictionary of the Ugaritic Language in the Alphabetic Tradition. Leiden.

Padró PARCErisa, J. (1976): Los materiales de tipo egipcio del litoral mediterráneo de la Península Ibérica. Universidad Autónoma de Barcelona.

PAdRó PARCERISA, J. (1985): Egyptian-type documents from the Mediterranean littoral of the Iberian Peninsula before the roman conquest. III. Study of the material, Andalusia. Brill, Leiden.

Padró Parcerisa, J. (1994): Un escarabeo egipcio inédito procedente de Gibraltar. Homenaje al profesor Presedo (P. Sáez y S. Ordóñez, eds.), Sevilla: 95-98.

PAdró PARCERISA, J.; (1995): New Egyptian-type documents from the Mediterranean littoral of the Iberian Peninsula before the roman conquest. Montpellier 1995.

Pecknam, J. B. (1968): The Development of the Late Phoenician Scripts. Harvard Semitic Series 20, Cambridge, Massachussetts.

Pérez López, I. (1998): Los santuarios de la Baetica en la Antigüedad: los santuarios de la costa. Libro Electrónico, Salamanca.

Posadas SÁnchez, J. L. (1988): Amuletos y divinidades egipcias en el Estrecho de Gibraltar prerromano. Nueva valoración de su influencia religiosa en el medio colonial: Actas del Congreso Internacional 'El Estrecho de Gibraltar'(E. Ripoll Perelló, ed.), I, UNED, Madrid: 517-527.

RAMÓN TorRes, J. (2006): La proyección comercial mediterránea y atlántica de los centros fenicios malagueños en época arcaica. Tiempos de Púrpura. Málaga antigua y antigüedades hispanas (M. Corrales, Mª C. Gontán, E. Martín, B. Mora y A. Recio, coord.), I, Mainake 28. Málaga: 189-212.

RAmón Torres, J. (2010): La cerámica fenicia del Mediterráneo extremo-occidental y del Atlántico (S. VIII - 1R. 1/3 del VI AC). Problemas y perspectivas actuales. Proceedings of the International Conference, Motya and the Phoenician Ceramic Repertoire between the Levant and the West $9^{T H}-6^{T H}$ Century BC. (L. Nigro, ed.), Quaderni di Archeologia Fenicio-Punica V. Roma: 211-253.

Ramón, J.; SÁez, A.; SÁez, A. M.; MuÑoz, A. (2007): El taller alfarero tardoarcaico de Camposoto (San Fernando, Cádiz). Junta de Andalucía. Sevilla.

Ruiz de Arbulo Bayona, J. (1990): Rutas marítimas y colonizaciones en la Península Ibérica: una aproximación náutica a algunos problemas. Italica 18: 79-116.

Ruiz Cabrero, L. A. (2010): La devoción de los navegantes. El culto de Astarté Ericina en el Mediterráneo. La devozione dei naviganti. Il culto di Afrodite Ericina nel Mediterraneo (E. Acquaro, A. Filippi y S. Medas, coord.). Biblioteca di Byrsa, Athenaion. Lugano: 97-135.

SÁez Romero, A. M. (2008): La producción cerámica en Gadir en época tardopúnica (siglos -III/-I). Vol. 1-2. British Archaeological Reports-International Series 1812. Oxford.

SÁez Romero, A. M. (2010): Comercio, procesado y consumo. Análisis evolutivo de algunas familias cerámicas gadiritas de época púnica y tardopúnica. De la cuina a la taula. IV Reunió d'Economia en el Primer Mil·lenni a. C. (C. Mata, G. Pérez y J. Vives-Ferrándiz, eds.), Sagvntvm Extra-9. Valencia: 303-312.

SÁez Romero, A. M. (2011): Balance y novedades sobre la pesca y la industria conservera en las ciudades fenicias del área del Estrecho. Pescar con Arte. Fenicios y romanos en el origen de los aparejos andaluces (D. Bernal, ed.). Catálogo de la exposición (Baelo Claudia, december 2011-julio 2012). Monografías del Proyecto Sagena, 3. Universidad de Cádiz: 255-297.

SAnMartín, J. (1986): Inscripciones fenicio-púnicas del sureste hispánico (I). Los Fenicios en la Península Ibérica (G. Olmo Lete y M. E. Aubet, eds.), AuOr 4, Sabadell: 89-103.

Untermann, J. (1990): Monumenta Linguarum Hispanicarum III: Die iberischen Inschriften aus Spanien-1. Die Inschriften. Wiesbaden.

Velázquez Brieva, F. (2007): El dios Bes de Egipto a Ibiza. Eivissa.

Waechter, J. D’A. (1951): Excavations at Gorham's Cave, Gibraltar. Preliminary report for the seasons 1948 and 1950. Proceedings of the Prehistoric Society 17: 83-92.

Waechter, J. D'A. (1964): The Excavation of Gorham's Cave, Gibraltar, 1951-54. Bulletin of the Institute of Archaeology of the Univ. of London 4: 189-221. 